\title{
Ecosystems as Spontaneous Orders
}

\section{Andy Lamey}

\section{Introduction}

The notion of a spontaneous order has long been used to advance a view of markets as complex networks of information that no single mind can apprehend. ${ }^{1}$ Traditionally, the impossibility of grasping all of the information present in the spontaneous order of the market has been invoked to reject central planning. In the hands of Friedrich Hayek, its most prominent proponent, such a view was used to argue for the superiority of capitalism. After the fall of the Berlin Wall thinkers in Eastern Europe invoked Hayekian arguments to explain the failure of Soviet-style communism. ${ }^{2}$ In recent years however Hayek's argument that modern economies cannot function effectively without the information signals contained in prices has been embraced by philosophers and economists sympathetic to Marxism. Writers such as G.A. Cohen, Meghnad Desai and Theodore Burczak endorse Hayek's critique of central planning while continuing to affirm some version of socialist values. ${ }^{3}$

\footnotetext{
${ }^{1}$ Hayek outlines several of the key features of a spontaneous order (without using the term itself) in, "The Use of Knowledge in Society," The American Economic Review, 35 (1945), 51930. Hayek's account is in turn influenced by that of Ludwig Von Mises. See his "Economic Calculation in the Socialist Commonwealth," first published in German in 1920 and republished in Collectivist Economic Planning F. A. Hayek ed. (London: George Routledge and Sons, 1935).

${ }^{2}$ See Vaclav Klaus, "The University of Chicago and I," in Renaissance: The Rebirth of Liberty in The Heart of Europe (Washington: The Cato Institue, 1997) and Anders Aslund Building Capitalism: The Transformation of The Former Soviet Block (Cambridge: Cambridge University Press, 2001), pp. 100-101, 392.

${ }^{3}$ G. A. Cohen, Why not Socialism? (Princeton: Princeton University Press, 2009), Meghnad Desai, Marx's Revenge: The Resurgence of Capitalism and the Death of State Socialism (London, Verso, 2002), Theodore Burczak, Socialism After Hayek (Ann Arbor, University of Michigan
} 
The partial embrace of Hayek by socialists belies his reputation as a thinker "associated with a pubic policy position, as opposed to a set of analytical arguments." ${ }^{4}$ Despite what Hayek himself may have thought, the use of his ideas is not limited to the applications he made of them. Importantly, in the case of his signature concept of spontaneous order, socialists are not the only ones who should seek to appropriate it. So too should environmental philosophers. Understanding ecosystems as spontaneous orders yields conclusions similar to those environmental ethicists have long argued for. Just as much as markets, ecosystems contain complex networks of information. And much as classical liberals and libertarians have sought to protect markets from what they perceive as misguided interventions by one particular institution, government, so too have environmental ethicists sought to protect the environment from misguided interventions by one particular species, homo sapiens. But while the spontaneous order concept is widely thought to have considerable explanatory power regarding the failure of central planning in the economic realm, so far overlooked has been its ability to explain why species extinction and related phenomena, such as the introduction of invasive species and global warming, are such a disaster on an environmental level. Species are similar to prices in being a crucial node of interaction in a larger complex system, the full details of which we cannot know. As such anthropogenic

\footnotetext{
Press, 2006). The compatibility of Hayek's principles with extensive regulation of the economy has long been noted by conservative and libertarian critics. For representative examples see Alan Ebenstein, Hayek: A Biography, (New York, Palgrave Macmillan, 2001), p. 381 note 32.

${ }^{4}$ Peter Boettke, "Why are there no Austrian socialists? Ideology, science and the Austrian school," Journal of the History of Economic Thought, 17 (1995), p. 35.
} 
species extinction can be viewed as akin to price control as a particular form of environmental manipulation that our limited knowledge rules out. ${ }^{5}$

A conceivable implication of extending spontaneous-order theory to environmental ends is that it commits its proponents to endorsing Hayek's political and economic views, which are controversial. It bears mentioning that the present account avoids any such outcome. One reason is because Hayek's free-market political views stem from the notion that markets, in particular, are spontaneous orders. It is possible however to grant that ecosystems are spontaneous orders but markets are not. Additionally, Hayek used the notion of spontaneous order in two separate arguments against socialism and social justice. One stressed epistemological considerations to argue for the limits of our abilities to engage in certain forms of economic planning. Hayek's second argument made a more purely normative claim, to the effect that the outcomes of spontaneous orders are not subject to considerations of justice. The case for viewing ecosystems as spontaneous orders draws on the first argument but not the second. It is thus consistent with the view that spontaneous orders, while they are not subject to certain forms of manipulation, are nevertheless appropriate subjects of moral analysis and concern.

An attractive feature of spontaneous order theory so understood is its ability to provide normative guidance regarding our interactions with the environment. This is in part due to the reality of environmental threats such as global warming. But the theory's attractiveness is also due to the ongoing division among environmental ethicists regarding the intrinsic value of non-

\footnotetext{
${ }^{5}$ Related views are discussed (in non-Hayekian terms) in The Virtues of Ignorance: Complexity, Sustainability and the Limits of Knowledge, Bill Vitek and Wes Jackson, eds. (Lexington: University of Kentucky Press, 2008)
} 
sentient life. A fault line has long existed in the environmental ethics literature between ethicists who view plants as intrinsically valuable, and ethicists whose sphere of moral concern extends at most to animals. The view that ecosystems are spontaneous orders recommends restraint in our dealings with the natural world, but it neither presumes nor denies that plant life has intrinsic moral value. Rather it can be endorsed by thinkers on either side of the intrinsic-value debate. While one intrinsic-value theorist, Holmes Rolston III, has drawn on a notion of spontaneous order in outlining an environmental ethic, it is not only fundamentally incompatible with Hayek's notion but also runs afoul of the fact-value distinction. A third and final appeal of the present account is that it is easily sidesteps this problem.

\section{What is Ecological Order?}

A possible drawback to Hayek's terminology is that it can inadvertently suggest an outdated view of ecosystems. In the early twentieth century Henry Gleason challenged the view, associated with Frederic Clements, that ecological communities follow a predictable pattern of growth and development, nalogous to that of an "superorganism." If one imagines a forest fire, for example, Clements argued that a forest will respond to such a disturbance by naturally growing back into a "climax community," understood as the distribution of vegetation best suited to the local environment. ${ }^{6}$ Gleason correctly noted that talk of a "climax community" overlooks the extraordinary degree of contingency and flux within ecological communities. A forest, rather than naturally growing toward a mature

\footnotetext{
${ }^{6}$ Odenbaugh, Jay. "Seeing the Forest and the Trees: Realism About Communities and Ecosystems." Philosophy of Science 74.5 (2007), 629.
} 
endpoint, is composed of dynamic and constantly changing elements thrown together by chance.

A Hayekian account of ecosystems, with its references to order, should not be misinterpreted as a rejection of this fundamental insight. The order it refers to exists at a higher level of abstraction and concerns the underlying regulative features of ecosystems. Such features were captured in Arthur Tansley's influential definition of an ecosystem as "the whole system (in the sense of physics), including not only the organism complex, but also the whole complex of physical factors forming what we call the environment of the biome." ${ }^{7}$

Tansley's definition includes biotic elements such as plants and animals and abiotic elements such as temperature, energy and volcanoes. The interactions between these elements, particularly as they involve the flow or exchange of nutrients and energy, is the underlying order a Hayekian account is concerned with. ${ }^{8}$ As S. T. A. Pickett and M. L. Cadenasso note, this definition of ecosystems is "not restricted to equilibrium, or complex, or stable systems. In fact, ecosystems may be far from equilibrium, so that they are changing in composition, content, or the processing of nutrients and energy." ${ }^{9}$ On this view ecosystems can be of different sizes and can be embedded within one another as parts of a whole. ${ }^{10}$ They can also include human beings and human artifacts, particularly (but not only) in urban

\footnotetext{
7 Tansley, Arthur G. "The Use and Abuse of Vegetational Concepts and Terms." Ecology 16.3 (1935), 299.

${ }^{8}$ The role of nutrients and energy is highlighted by Jay Odenbaugh. See "On the Very Idea of an Ecosystem," in New Waves in Metaphysics, Allan Hazlet ted. (Palgrave: New York, 2010), 247.

${ }^{9}$ Pickett, S. T. A, and M. L Cadenasso. "The Ecosystem as a Multidimensional Concept: Meaning, Model, and Metaphor.” Ecosystems 5.1 (2002), 2.

${ }^{10}$ Odenbaugh, "Seeing the Forest and the Trees," 640.
} 
settings. ${ }^{11}$ In all of these ways ecosystems are similar to economies, which are also dynamic, exist within and alongside one another, and of course include human beings. On such a view, there is no implication that ecosystems are fundamentally static or working toward a state of balance or equilibrium at the level of either their biotic or abiotic components.

\section{Spontaneous Orders}

Hayek argued that there are orders in society that are the result of human activity but not of human design. He often cited the example of language. On his account it is the result of a process of evolution, the endpoint of which no one predicted or organized. Similarly, in the economic sphere, Adam Smith famously described the market as an invisible hand in which the individual is led to promote ends which he does not deliberately intend. Hence Smith's famous remark about the self-interest of the butcher providing us with our dinner. Hayek follows Smith by characterizing the market as a paradigmatic spontaneous order, one that no individual has designed and which aims at no particular purpose.

Spontaneous orders have a number of other distinguishing characteristics. These can perhaps best be seen by contrasting them with made orders, which are relatively simple and contain only as much complexity as their creator can grasp. Legal codes, firms, bowling leagues, universities: all would count as made orders in Hayek's sense. Such orders are concrete, in the sense that they can be identified by sensory inspection, and serve particular purposes as determined by their makers.

In the case of a spontaneous order the opposite is the case. Spontaneity is not the same as complexity, and a spontaneous order can be small-scale and

\footnotetext{
${ }^{11}$ Pickett and Cadenasso. "The Ecosystem as a Multidimensional Concept," 2.
} 
simple. Hayek gives the example of iron filings made to arrange themselves along the line of force of a magnet. Nevertheless, unlike made orders spontaneous ones can exhibit truly enormous complexity. One of Hayek's main contentions is that highly complex orders, comprising as they do more facts than any individual mind could ascertain, can only be brought about by forces which induce the formation of a spontaneous order, a category which does not include a mind trying to deliberately create such an order.

It is not a necessary condition of being a spontaneous order that it be abstract. But again unlike made orders, spontaneous orders can be composed of abstract components, as when for example a price is generated in the derivatives market. It is a necessary condition of being a spontaneous order that it was not created by any outside entity. As such, it has no set end. (This is true, Hayek notes, "even though its existence may be very serviceable to the individuals which move within such order."12) There are thus elements of a spontaneous order that act to maintain the order, in the sense of allowing it to continue to exist through time; but these elements maintain the order without bestowing it with a purpose per se, or preventing the contents of the order from existing in a state of constant flux.

Hayek's central example of a spontaneous order is the market. His analysis is meant to warn us off certain forms of market interferences, in particular those which seek to control prices. Such forms of intervention are counterproductive on Hayek's view, as the price of a good is the result of a wide variety of factors, the sum total of which no individual is able to know. As

\footnotetext{
${ }^{12}$ F. A. Hayek, Law, Legislation and Liberty Volume I: Rules and Order (Chicago: University of Chicago Press, 1973), p. 39.
} 
Hayek puts it, if we want to understand the price system, we need to recognize that is a "mechanism for communicating information":

The most significant fact about this system is the economy of knowledge with which it operates, or how little the individual participants need to know in order to be able to take the right action.... It is more than a metaphor to described the price system as a kind of machinery for registering change, or a system of telecommunications which enables individual producers to watch merely the movement of a few pointers, as an engineer might watch the hands of a few dials, in order to adjust their activities[.. $]^{13}$

To take Hayek's example, if a product such as tin becomes scarce, it does not matter to the potential purchaser whether this is because one of its sources has dried up, or because a new use for tin has arisen. In either case the price goes up, and this is the only information the purchaser needs to know in order to decide whether or not to buy. Were a central planner to seek to impose a price on the tin market it would only throw the market into disequilibrium, as the balance of forces created by supply and demand would be destroyed by superimposing our preferred result on the order's outcome. ${ }^{14}$

The value of prices is that they obviate the need to access knowledge that it is impossible for a planner to obtain, "the knowledge of the particular circumstances of time and place." ${ }^{\prime 15}$ Hayek gives the examples of a shipper who makes his living sending goods on otherwise half-empty trampsteamers and a real estate agent whose livelihood hinges on being aware of

\footnotetext{
${ }^{13}$ F. A. Hayek, "The Use of Knowledge in Society," p. 527.

${ }^{14}$ Law Legislation and Liberty Vol I., p. 51. Hayek's reference to "balance" should not be taken to entail the myth of the balance of nature critiqued by Daniel Botkin. See "Adjusting Law to Nature's Discordant Harmonies," Duke Environmental Law \& Policy Forum, 7 (1996), 25-38. Prices of stocks and other goods are frequently in a state of flux, and the balance here is a highly dynamic one.

${ }^{15}$ F. A. Hayek, “The Use of Knowledge in Society," p. 522.
} 
changing and temporary opportunities in the local housing market. Both commercial actors perform highly useful activities "based on special knowledge of circumstances of the fleeting moment not known to others."16 The limits on our ability to aggregate the shifting and specific knowledge they and countless other market actors possess is what makes prices so serviceable - they consolidate and communicate all the information we need to make economic decisions.

Hayek's critics have long argued that markets do not really match his description of a spontaneous order. ${ }^{17}$ Such a criticism stresses the role government plays in enforcing contracts, copyright and other legal mechanisms which make markets possible. Perhaps in response to this view, Hayek allowed that it is "at least conceivable that the formation of a spontaneous order relies entirely on rules that were deliberately made." ${ }^{18}$ In such instances, he suggested, we must distinguish the spontaneous character of the resulting order from the non-spontaneous origins of the rules or regularities which made the order possible.

How this view accords with Hayek's more frequent stress on the selfgenerating nature of spontaneous orders is not clear. Hayek seems to moot the possibility that a spontaneous order is distinct from the conditions that bring it into being, but offers little argument for such a view. What is important for our purposes however is to note that the concept of

\footnotetext{
${ }^{16}$ F. A. Hayek, “The Use of Knowledge in Society," p. 522.

${ }^{17}$ Steven Lukes, "Invasions of the Market," From Liberal Values to Democratic Transition: Essays in Honour of János Kis, Ronald Dworkin ed. (Budapest: Central European University press, 2004), p. 69; Amaratya Sen, Poverty and Famines: An Essay on Entitlement and Deprivation (Oxford: Oxford University Press, 1981), p. 166.

${ }^{18}$ Hayek, Law, Legislation and Liberty, p. 46.
} 
spontaneous order is larger than that of the market. Hayek's examples of spontaneous orders include an individual organism, crystals, complex organic compounds such as chemicals, the distribution of iron filings on a piece of paper held over a magnet, cultural customs, portions of the law and moral codes. ${ }^{19}$ Although markets are Hayek's primary concern, the generalizations Hayek makes about spontaneous orders extend beyond them.

This is worth emphasizing because it is possible to endorse the notion of a spontaneous order without committing oneself to the view that markets are spontaneous orders. Hayekian economic and philosophical views are controversial, and the notion that ecosystems are spontaneous orders will seem unattractive to some if it entails endorsing laissez-faire premises. But it is perfectly consistent to maintain that ecosystems are spontaneous orders while denying that markets are. One can for example endorse the commonly stated view that because markets depend crucially on government enforcement of contracts, as Hayek himself admits, it is misleading to characterize them as spontaneous in any fundamental sense, and instead hold that they are appropriately regulated to a greater degree than Hayek would allow. Such a view is only consistent with denying that there is any equivalent external force which maintains ecosystems and which makes them appropriately subject to a high degree of intrusive management. For anyone uncomfortable with Hayek's demarcation of the economic and political landscape, therefore, the application of the spontaneous order concept to natural ecosystems includes a golden road of escape.

\section{Ecosystems as Spontaneous Orders}

\footnotetext{
${ }^{19}$ Law, Legislation and Liberty Vol I., pp. 37 (organism); 39-40 (crystals, complex organic compounds, iron filings); 46 (law, morals, customs).
} 
The upshot of Hayek's analysis was invariably to argue for some form of non-intervention in the market. In making his case, Hayek frequently invoked examples of spontaneous orders in the natural world. Given this it would seem natural to ask whether we might also have some obligation of non-intervention concerning spontaneous orders in nature.

The first step in answering this question is to note the obvious ways in which ecosystems match Hayek's description of a spontaneous order. If anything can fairly be described as self-generating their underlying process of energy and nutrient echange can. Human beings arrived into a world in which ecosystems already existed, and if we were to disappear they would live on after us. And while natural systems may have many functions, it is only consistent with evolutionary theory to say they have no purpose, let alone a conscious mind directing them. Hayek stressed that any large scale economy is really the sum total of numerous inter-related economies. ${ }^{20}$ This idea of orders-within orders applies equally to the case of ecosystems, whose internal elements are constantly interacting with one another, and which see local ecosystems existing as part of larger regional and ultimately global ones.

Finally, and perhaps most crucially, ecosystems are subject of enormous amounts of constantly changing information which it is impossible for us to ever be fully cognizant. Ecological relations include interbreeding, and "competition for shared resources such as food, light and habitat... Likewise, ecological communities are causally connected through predator prey, interspecific competition, mutualism, amensalism, commensalism, and

\footnotetext{
${ }^{20}$ Law Legislation and Liberty Vol. II, p. 108.
} 
so on, relations." ${ }^{21}$ This web of relations is just as dynamic and complex as that found in markets. To be fully aware of what was happening in every given relation at any given time it would require extensive knowledge of time and place, or the same type of aggregate information that Hayek characterized as being beyond the reach of central planners. In the environmental case just as much as the economic one, it is unlikely we will even be able to ascertain complete knowledge of all the diverse elements that make up the global ecosystem.

\section{Two Kinds of Ecological Ignorance}

There are ways in which our ignorance of ecosystems differs from our ignorance of the factors driving prices. It may be helpful therefore to distinguish two different kinds of ignorance regarding the natural world, in order to clarify which kind is relevant to a spontaneous order-based account.

The first type of ignorance concerns our limited awareness of what the natural world contains. One 2011 study estimated that the total number of species on planet earth is 8.7 million, plus or minus 1.3 million, of which only 1.3 million have been catalogued.$^{22}$ Such figures reveal the scope of our current ignorance of all the elements found in the natural world. It is sobering to note that habitat loss has been identified as a primary threat to 85 percent of the species included in the International Union for the Conservation of Nature's Red List of threatened or endangered species. This

\footnotetext{
${ }^{21}$ Odenbaugh, "On the Very Idea of an Ecosystem,” 241.

${ }^{22}$ C. Mora, D. Tittensor, S. Adl, A Simpson, B. Worm. “How Many Species Are There on Earth and in the Ocean?" PLoS Biology 9 (2011), e1001127. The study has been criticized for underestimating the total number of species. See C. Zimmer, "How Many Species? A Study Says 8.7 Million, but It's Tricky," The New York Times, August 30, 2011.
} 
dispiriting trend must be causing the extinction of a large number of species that will never be known to us in living form.

As tragic as our ignorance of countless species is however, it is not the type of ignorance that the spontaneous order model emphasizes. The precise number of all species on the planet is knowable: scientists are estimated to discover 15,000 new species every year. ${ }^{23}$ As glaring as our current ignorance of planetary life is, therefore, it is the kind of information that could be ascertained. Certainly it is knowledge that a single mind can in principle apprehend.

The ignorance spontaneous order theory is concerned with has to do with the permanent limitations of our factual knowledge: up-to-date information about the internal flux of a dynamic order. ${ }^{24}$ In the case of prices, if we sought to investigate the exact nature of all the factors influencing them on a given day, they would be too diverse and ever-changing to identify. Our ignorance regarding the total number of species in existence at a given time involves a more or less static body of knowledge. Our ignorance concerning the teeming interactions of countless different organisms, by contrast, concerns a dynamic subject. It is the latter type of ignorance and the limit it places on our ability to successfully manipulate nature that the spontaneous view emphasizes.

\section{Species as System Input and Output}

Much of Hayek's analysis concerned the special undesirability of interfering with prices as opposed to other forms of economic intervention. Are there any natural elements that play a similar role in spontaneous natural

\footnotetext{
${ }^{23}$ See Zimmer, 2011.

${ }^{24}$ Hayek, Law, Legislation and Liberty Vol I, p. 11.
} 
orders, standing as the ecological element that we should be especially loath to manipulate?

Answering this question requires recalling just why price interference is unattractive. Price-setting by a central planner targets the most visible output of a larger system of information circulation and exchange. Crucially, the spontaneous price is both an output and an input, the place in the system that allows the forces of supply and demand to interact. The disappearance of the unplanned price thus has a follow-on effect elsewhere in the system, causing it to cease functioning. In the case of tin, the supply either dries up or finds an outlet on the black market, and the price of replacement metals and/or goods normally made from tin will also be disrupted. Are there any elements in an ecosystem that play a similar double-sided role? That is, are there visible elements which are formed by invisible forces within a larger system, and which in turn influence the actions of other elements in the system?

The most plausible candidate is species. ${ }^{25}$ In the case of both plants and animals it is the product of the countless actions of individual organisms. Its birth is the product of a variety of competitive forces: those between the individual members of its immediate ancestor species; between its ancestor species and its environment; and between its ancestor species and other species. These competitive forces combine in unpredictable ways to create a new form of life. Our ability to manipulate these processes in a manner that results in ecosystem-sustaining outcomes is severely limited by our ignorance

\footnotetext{
${ }^{25}$ I do not take sides in the debate as to whether species are individuals, sets "homeostatic property clusters," etc. My account is compatible with any of these views and with some forms of species pluralism. For an overview of the debate see Richard Richards, The Species Problem: A Philosophical Analysis (Cambridge: Cambridge University Press, 2010).
} 
of time and place concerning the many different entities that contribute to the creation of a species.

To illustrate this imagine an attempt to artificially recreate a species. Let us start with a species that is extinct. It is possible to know what a dodo looked like and what its typical behaviors were, such as its inability to fly. It is also in principle possible to know how many dodos lived on Maritius, their natural habitat, pre-extinction. And it may someday even be possible to duplicate this number in the form of dodo-like android that mimic dodo behaviours, which we might even release into the Maritian wild.

The present account does not rule out the possibility that releasing the robotic dodos could have limited value as a form of environmental restoration. But now suppose we wished to program the mechanical birds so that they mimicked the movements that the original dodo population would have engaged in had its members continued to exist. On a day when $x$ number of organic dodos would have been found in a certain area of a forest, the same number of synthetic dodos would now be found there. However many organic dodos would have eaten fruit that day; or laid an egg; or sought shelter from the rain; or left the forest to seek food by the shore; or died-our synthetic dodos would be programmed to engage in all the identical behaviors in the same places at the same time.

It is the knowledge required for this kind of programming that is permanently unknown to us. Crucially, it would be impossible to apprehend even if dodos still existed and we were able to capture all the dodos on Mauritus and replace them with synthetic birds. An awareness of the location of every migrating pod of whales or murder of crows, and their interactions with each other, with other species and with their larger environment-all 
this is just as unpredictable as the location of every source of tin or person in need of tin cans. In the case of ecosystems, we would need to predict the interactions of not just one species but many, as well as all the changes they caused in the environment, and which the environment in turn caused on other animals.

The difficulty of knowing the many diverse interactions of countless individual organisms is especially brought home when we recall that evolution remains an ongoing process, with new species still appearing. When we try to imagine predicting in advance the make-up of future species we come to a final parallel to Hayek's account of prices. Hayek once quoted with approval the observation of a previous writer that "no scientist has ever used [evolutionary] theory to foretell the coming into existence or creatures of a novel species, still less verified his forecast." ${ }^{26}$ Hayek did not have an environmental application of his philosophy in mind when making this remark, but it speaks to such a concern. Nothing may be less knowable than the biodiversity that would otherwise arise when we intervene in nature in a manner that causes species loss.

One thing we do know is that when ecosystems are left to their own devices many of their individual elements may come and go but their underlying processes of energy and nutrient exchange are likely to maintain themselves through time in a manner that sustains all of our environmental needs. We do not know that we can intervene in nature in such a way as to achieve the same end, let alone improve on nature's ability to perpetuate itself. Our ignorance makes the chance of unwanted unsustainable outcomes

\footnotetext{
${ }^{26}$ F. A. Hayek, "The Theory of Complex Phenomena," in Studies in Philosophy, Politics and Economics ( London, Routledge \& Kegan Paul, 1967), p. 31.
} 
very high. Such a pessimistic view is born out by the current state of the global environment, which has seen a dramatic loss of species diversity. Given this reality we are well advised when considering two courses of action to prefer the one that, all else being equal, impacts species diversity the least.

In this way species play a role broadly analogous to that of prices. A species is in its own manner a visible node in a larger system containing many invisible elements which will remain unknowable to us, precisely because of their ever-changing nature. In the natural domain just as much as the economic one, we are faced with dynamic systems which we cannot entirely master. Our ability to manage both systems is limited, in that there are circumstances in which it will be best not to seek to make it produce a preferred outcome, whether directly in the form of wage and price controls or in the more indirect manner that is more typical in the case of ecosystems. To be sure, in an environmental context, no one deliberately set out to make grey whales critically endangered the way central planners deliberately seek to set prices. Species loss is usually the by-product of another goal, such as clearcutting a wilderness to build a subdivision or establish a mine. What is important however is not the conscious intention of our actions but their effect. Destroying a rainforest to build a highway is an intrusion, insofar as we delimit the area in which species can function and perpetuate themselves. It is debatable whether animals possess knowledge the way Hayek's examples of the shipper and real estate agent do. Even so, the analogy between economic and ecological ignorance does not depend on there being a knower in the natural world who is self-consciously aware of local particulars the way human economic agents are. What is important rather is the way 
species, like prices, can function as proxies for a much larger body of information. The presence of a species in its natural habitat is also due to countless individual actions of fleeting moments unknowable to us. When we allow an ecosystem to sort out for itself what species it will possess, we will not be able to articulate all of the precise natural interactions which determined the final total. Nevertheless, the presence of such species plays a broadly similar role of condensing and assimilating large amounts of information unknowable to an external observer. The smaller the number of such species that are made extinct or endangered by humans, the healthier we can take the ecosystem to be, even if we are unable to articulate the many different instances in which a particular species contributes to ecosystem health or the ways in which it typically does so. Crucial to know is that its presence in the ecosystem is naturally occurring. The more we can be sure of this, the more we can be sure that a condition of ecosystem health has been met.

On this approach there is an important difference between the economic and environmental cases. In the latter we need to identify whether or not a species is native, and whether its numbers have been decimated by human beings. This is admittedly a higher cognitive burden than we face in the economic realm, when we need to know the price and only the price. But this difference does not affect the central similarity, which is the idea of the native species serving as a signal that renders it unnecessary to obtain a much larger body of knowledge which it is impossible for us to know, namely the knowledge of all the particular actions which caused the species to become a natural part of the ecosystem. When the ecosystem is allowed to determine for itself which species it contains we can take it for granted that the presence 
of any given species is performing servicable functions, even if we are unable to say precisely what they are.

None of this is to suggest that species signals and price signals play precisely identical roles. One is hard pressed for example to think of an ecological equivalent to black markets, which are a predictable consequence of central planning. Nevertheless, to intervene in an ecosystem and deprive it of a species is to create an impact on it that has a disruptive follow-on effect on the larger system. As Hayek writes in one of many passages that apply to an ecosystem just as much as markets, "there will be many aspects of it over which we will possess no control at all, or which at least we shall not be able to alter without interfering with—and to that extent impeding —-the forces producing the spontaneous order." 27

\section{Ramifications of the Spontaneous Order View}

Characterizing ecosystems as spontaneous orders will have normative ramifications so long as we endorse the uncontroversial view that we have moral obligations not to harm human beings. Human beings depend on healthy ecosystems for their own health and survival. As a result we cannot be indifferent to the fate of ecosystems. Yet if ecosystems are properly understood as spontaneous orders we must acknowledge that they are all too easily damaged by anthropogenic species loss. Hence we have a prima facie reason to limit human-caused extinctions.

Such a reason is only strengthened if we recognize animals as subjects of moral concern. But whether or not we recognize moral claims on behalf of animals, our rationale for preferring environmentally sustainable outcomes over non-sustainable ones, all else being equal, does not presuppose that the

\footnotetext{
${ }^{27}$ Law Legislation and Liberty Vol. I, p. 42.
} 
non-sentient life within ecosystems possess intrinsic moral value. Although such a view has long been prominent in the environmental ethics literature the present account needs only presuppose that human beings, at most, posses direct moral standing. It is when this uncontroversial view is combined with the spontaneous order view of nature that the latter's normative implications emerge. While such an account generates a de facto obligation to preserve the non-sentient life in natural systems, this is because doing so meets our obligation not to harm human (and perhaps other) beings.

One can draw an analogy here to an application on a computer which performs an important function, such a browsing the Web or creating a document, beyond actually operating the computer itself. Even though computer applications requires an operating system to work, the question of what applications a computer has is crucial to determining its functionality. We see the importance of individual applications most clearly when they allow us to perform some function we especially value. Understanding ecosystems as spontaneous orders is the philosophical equivalent of an application in that it is compatible with more than one moral operating system, whether that system recognizes moral standing in anthropocentric, zooocentric or ecocentric terms.

This compatibility with different background systems is part of what makes the model attractive. So is the fact that even when it is added to a moral framework which recognizes only human standing, it still generates normative reasons for environmental preservation. (When it is combined with frameworks that recognize animal and plant standing it adds to the reasons such approaches already recommend for environmental protection). 
This is a significant ramification of the model, even if an antecedent moral framework is also required for it to generate normative conclusions.

Viewing ecosystems as spontaneous orders does not entail that changing the natural environment is always wrong. Part of Hayek's argument has to do with scale. His argument leaves open the possibility that socialism could work in small face to face groups. It is when we confront the diffuse information that makes up something as large an impersonal as a modern economy that we find our ignorance a serious barrier. Similarly, on a natural level we can maintain a garden without concern that doing so will cause the local ecosystem to collapse. But were we to seek to transplant the principles that govern our interactions with the garden to the broader ecosystem we would be courting disaster. For in the case of the latter we encounter a large and complex network of information that resists our ability to manipulate it.

The present view does not entail that we must preserve species at all costs. When a species goes extinct naturally this is no cause for alarm, as nature is taking its course. The outcome may be the same as with anthropogenic extinction, but the process by which it occurs is very different. In one case but not the other we can be confident that the extinction will not erode an ecosystem's ability to perpetuate the ongoing existence of its biotic components. Indeed, natural extension is properly viewed as one of the means by which ecosystems ensure their ongoing existence.

Anthropogenic extinction is different. In such cases we cause nature to go off course as it were by denying it one of the elements it has traditionally used to perpetuate itself. When a species goes extinct due to human impacts on the environment, we should be aware that this can and often does have a negative impact on the ecosystem in which the species lived. in particular we 
can no longer take it for granted that the ecosstem's ability to sustain human and other life has not in some way been limited or compromised. This is the case, we have seen, even though we will not be able to articulate all of the negative effects of any given extinction.

A concern with minimizing anthropogenic species loss will have additional ramifications beyond a concern with avoiding actions which directly cause such extinctions. There is also the closely related issue of invasive species, or those introduced into an ecosystem by human beings. A well-known example concerns the introduction of cane toads into Australia in the 1930s. Originally introduced to control the cane beetle population, they became widespread and caused the depletion of native species and fauna, poisoning of animals and humans and other ongoing problems. More recently, invasive plant species have become so common in Australia that they total 17 percent of all wild plant species on the continent and cost the Australian economy more than three billion dollars a year. ${ }^{28}$

The Australian experience illustrates a global trend. Invasive plants commonly benefit from the habitat degradation they cause by facing less competition for resources. They thus often colonize their new habitat and make a significant contribution to species loss. This negative process has been termed the McDonaldization of world ecology, in that exotic species are closely associated with a reduction in species diversity. ${ }^{29}$ In the words of ecologist Stephen Goosem, "we have created a situation in which a

\footnotetext{
${ }^{28}$ Stephen Goosem, "Invasive Weeds in the Wet Tropics," Living in a Dynamic Tropical Forest Landscape, Nigel Stork and Stephen Turton eds. (Oxford: Blackwell, 2008), p. 308.

${ }^{29}$ Tim Low, Feral Future: The Untold Story of Australia's Exotic Invaders (Melbourne: Viking, 1999).
} 
tremendous mixing of plant species is occurring to the extent that it has become an important component of human-induced global change." 30

It does not seem realistic to think that we might continue to introduce invasive species but halt the problems they cause after the introduction stage. Thus, in addition to an obligation to not cause species loss directly, we also have a pro tanto obligation not to introduce additional exotic species. This is because we are again in a situation of ignorance when it comes to imagining the precise distribution of other living things and landscape elements that would have been the case without the new species. We are unable to apprehend and the countless instances of interaction they would have engaged in and the ongoing dynamic effects on the local and other ecosystems. Crucially, this includes events that might be steps toward the evolution of a new species or new habitat for an existing species. As with direct species loss, invasive species have a negative follow-on effect on the larger ecosystem, all the aspects of which we may not know.

If the spontaneous order model can explain why we should avoid causing extinctions and introducing exotic species, it can also explain why global warming is to be avoided. Anthropogenic warming is one of the most extensive systematic changes imaginable, one with countless consequences beyond the global temperature itself. Staying with extinction, we need only look at a recent scientific examination of the possible effects of global warming on 25 biodiversity hotspots that account for 44 percent of global plant species and 35 percent of vertebrate animal species. The study found that the widely predicted trend of a doubling in global carbon-dioxide levels could result in a loss of 56,000 plant and 3,700 endemic vertebrate species in

\footnotetext{
${ }^{30}$ Goosem, "Invasive Weeds," p. 308.
} 
the affected regions. ${ }^{31}$ A separate multi-region study predicted that global warming will see 18-35 percent of animal and plant species committed to extinction by 2050 depending on the degree of global warming that is allowed to occur. ${ }^{32}$ This much we can know: unchecked global warming will be an ecological disaster. A concern with the irreplaceable unit of the species is thus connected to other issues, and can ground our concern with preserving biodiversity and halting global warming, two destructive impacts on the natural world that erode the ability of spontaneous ecological orders to comfortable support human and non-human life.

\section{Manipulating Species, Manipulating Nature}

The present analysis does not imply that all forms of species manipulation are wrong, let along that manipulating the environment itself must always be avoided. We manipulate species in many different ways other than causing the to go extinct. One obvious way is through efforts which seek to restore the numbers of a species that has become critically endangered due to human action. This is a form of species manipulation just as much as anthropocentric extinction is. The later cases however is corrective, and seeks to restore the a natural system a node that human action has eliminated. It seems reasonable to place the two forms of manipulation, one disruptive the other corrective, in different categories. Unlike species extinctions, species restoration efforts do not remove from nature a primary unit of self-maintenance. Rather they replenish natural systems by working directly against such losses.

\footnotetext{
${ }^{31}$ J. Malcolm, C. Liu, R. Neilson, L. Hansen L Hannah. "Global warming and extinctions of endemic species from biodiversity hotspots," Conservation Biology 20 (2006), 538-48.

${ }^{32}$ C. Thomas, A. Cameron, R. Green, M. Bakkenes; L Beaumont; Y. Collingham; B. Erasmus;

M. Siqueira; A. Grainger; L. Hannah. "Extinction risk from climate change," Nature 427 (2004), 145-148.
} 
Speaking of interventions in markets, Hayek remarked that "'interference' implies the operation of a process that proceeds by itself on certain principles because its parts obey certain rules. We would not call it interference if we oiled a clockwork, or in any other way secured the conditions that a going mechanism required for its proper functioning." ${ }^{33}$ This remark suggests that actions by outside entities affecting spontaneous orders are not always to be lamented. Actions which contribute to the same outcome as the order does when left to its own devices will be in harmony with that order. Of course we might wonder if we will ever be in a position to know in advance the outcome of a particular order. But what is worth considering is the thought that interventions in a spontaneous order can be disruptive to a greater or lesser degree.

It is against this backdrop that we can distinguish the above-mentioned case of releasing cane toads into Australia from efforts to re-introduce an endangered species into its natural habitat. Both involve human beings introducing animals into an ecosystem. In the first case the action involves the introduction of an exotic species. But in cases of the latter kind the reintroduction is an attempt to mitigate the negative effects of previous human actions, such as habitat destruction or hunting, which caused the species to disappear from the local ecosystem. The reintroduction thus "follows nature's lead" by restoring the species which short-sighted human action placed under stress. This is very different from the destructive action represented by releasing an exotic species into the wild. Re-introduction is in keeping with an ecosystems natural workings whereas exotic introductions are not. This is why in the robotic dodo scenario it is acceptable to attempt re-

\footnotetext{
${ }^{33}$ Hayek, Law Legislation and Liberty Vol. II, p. 128.
} 
introduction, even though reintroduction can never be a full substitute for a species continued uninterrupted existence.

It is necessary to distinguish between different ways of manipulating species and ecosystem in nature because our relationship with the latter is not only one of distance. It is also one of cultivation. It is a myth to think we might never "intervene" in nature. There is rather a rough ecological equivalent to Hayek's distinction between the grown and the made order, in the difference between natural and domesticated landscapes. Hayek speaks of the family, the plant and the firm as examples of organizations, and it is tempting to view the farm, the field and the greenhouse are their organic equivalents. Hayek's contrast however was a sharp one, noting that direct commands had a place within an organization. When it comes to domesticated zones, however, there is a limit even here to how we can manipulate them: we are still at the mercy of insects, drought and hurricanes when it comes to farming, for example. We can manipulate farmland to make it more fecund, but must do so in a manner mindful of the natural systems of domesticated plants and animals. The boundary between a grown and a made landscape can also change. This does not mean we can regard every ecosystem simply as a cultivated acre in waiting. For all the reasons I have been mentioning, it is a mistake to think we can take all or even most of nature under our control.

Nevertheless, it is very much the case that human beings need to manipulate nature. Given the inevitability of our involvement and interaction with ecosystems, it bears noting what the spontaneous order model says about such activities. While it rules out species extinction and related 
activities which contribute to it, it does not posit a view of nature as something apart from us which we can never seek to manipulate or change.

Consider the practice of geoengineering, one of the most profound forms of environmental manipulation now possible. In the age of global warming, we have become familiar with cap and trade schemes or proposals for a carbon tax. What such solutions have in common is that they would reduce the overall amount of greenhouse gas released into the atmosphere. On both approaches the solution to global warming is not more atmospheric interventionism but less. Geoengineering is based on the opposite approach. It has been defined as the "intentional manipulation of planetary systems at a global scale," and is commonly put forward as a means of addressing anthropogenic climate change.$^{34}$ One proposal for example is to cool the surface of the earth by releasing sulfate aerosols into the stratosphere that would function as a shield against incoming radiation. ${ }^{35}$ Another proposal, put into effect off the coast of Western Canada in 2012, involved an attempt to fertilize the ocean through large-scale deposits of iron sulphate, the goal being to increase the population of phytoplankton, an absorber of carbon dioxide.

Such schemes attracted accusations of "ecopiracy," with critics arguing that their long-term effects are unknown and potentially destructive. ${ }^{36}$ On the

\footnotetext{
${ }^{34}$ Stephen Gardiner, "The Desperation Argument for Geoengineering," PS: Political Science and Politics, 46 (2013), p. 28.

${ }^{35}$ A. Robock, A. Marquardt, B. Kravitz, G. Stenchikov. "Benefits, risks, and costs of stratospheric geoengineering," Geophysics Research Letters, 36 (2009), 1-9.

${ }^{36}$ Action Group on Erosion, Technology and Concentration, "World's Largest Geoengineering Deployment Off Coast of Canada's British Columbia," accessed 29 April 2013, <http: / / www.etcgroup.org/ content/ world's-largest-geoengineering-deploymentcoast-canada's-british-columbia>.
} 
spontaneous order account it will turn out as no surprise if such efforts prove less effective than attempts to combat global warming that involve reducing the human impact on the environment. It will only show once again that there is a complexity to ecosystems that exceed our attempts at mastery. Nevertheless, only some forms of geoengineering are categorically ruled out on the present account. These are geoengineering projects that directly or indirectly contribute to anthropogenic species extinction. Forms of geoengineer that avoid this outcome are not something that can be judged at an a priori level. It is an empirical question whether any given one can achieve some benefit, and so they must be judged on a case by case basis. In this way geoengineering projects which do not reduce species diversity stand in for all other forms of environmental manipulation that also avoid humancaused extinction. They are in a different category from manipulations which remove from an ecosstem one of the central nodes through which its various elements interact, develop and evolve.

\section{Spontaneous Order Versus Intrinsic Value}

I have now made the central case for thinking of ecosystems as spontaneous orders. There is however an additional aspect of the model worth mentioning. A major concern of environmental ethicists has long been to argue against environmentally disruptive practices. For many ethicists the basis for this stance has been the intrinsic value of all life, including nonsentient life. ${ }^{37}$ Such a view however has been subject to powerful criticisms. ${ }^{38}$

\footnotetext{
${ }^{37}$ Paul Taylor, Respect for Nature: A Theory of Environmental Ethics. (Princeton: Princeton University Press, 2011); Holmes Rolston III, Environmental Ethics. (Philadelphia: Temple University Press, 1989).
} 
Given this, it is an advantage of the spontaneous order view that while it too places limits on the degree to which we can hope to disrupt the natural world, it does not require endorsing the view that plants have moral standing.

This aspect of the spontaneous order model is worth stressing, for there is a rival view which invokes the spontaneity of natural systems as grounds to argue for the intrinsic value of non-sentient life. Holmes Rolston III mentions the idea that ecosystems are spontaneous orders in making the case for direct duties toward nature. As Rolston puts it:

There is a kind of order that arises spontaneously and systematically when many self-concerned units jostle and seek their own programs, each doing their own thing and forced into informed interaction with other units. In culture, the logic of language or the integrated efficiency of the market are examples. No one individual orders either of these, but there is much rationality in both. In nature, an ecosystem systematically generates spontaneous order, an order that exceeds in richness, beauty, integrity, and dynamic stability the order of any of the component parts, an order that feeds (and is fed by) the richness, beauty, and integrity of these component parts.

Hayek is not mentioned by Rolston, who may not have been aware of the Hayek's use of "spontaneous order" as a term of art. Hayek for example thought that associating markets with reason was but a step on the road to central planning: he would thus never exclaim about how much rationality they contain. That difference aside, there is an obvious similarity between

\footnotetext{
${ }^{38}$ Peter Singer, “A Response," in Jamieson, Dale, ed. Singer and his critics. (Oxford: WileyBlackwell, 1999), 327-35; Andrew Brennan, Thinking About Nature. (Athens: University of Georgia Press, 1988).
} 
Hayek and Rolston. Both write of decentralized systems that are selfgenerating and self-sustaining and cite markets and ecosystems as examples.

This similarity however is accompanied by a crucial difference. Rolston goes on to argue that the richness, beauty and integrity of an ecosystems are markers of its intrinsic value. Rolston here draws an analogy between our evaluation of an ecosystem and a culture. A culture is rich, diverse and beautiful because it is the creation of a huge number of different intellects, outstripping the value of anything under the centralized control of a single consciousness. "Analogously, ecosystems are in some respects more to be admired than any of their component organisms, because they have generated, continue to support, and integrate tens of thousands of member organisms. The ecosystem is as wonderful as anything it contains." ${ }^{39}$ The spontaneity of an ecological order on Rolston's account is thus not only something we should admire but something that makes ecosystems "places of value capture" and thus subjects of moral concern. ${ }^{40}$

This understanding of the relationship between a spontaneous order and moral value is very different from anything found in Hayek. According to Hayek, just and unjust are concepts best reserved for analysis of human conduct. "If we apply the terms to a state of affairs, they have meaning only in so far as we hold someone responsible for bringing it about or allowing it to come about." ${ }^{41}$ For this reason Hayek argued that the concept of justice had no application to the outcome of a spontaneous order. If we think of the overall distribution of wealth in society, it is the outcome of human action in

\footnotetext{
${ }^{39}$ Holmes Rolston III, “Duties to Ecosystems," in Companion to A Sand County Almanac, J. Callicott ed. (Madison: University of Wisconsin Press, 1987), p. 257.

${ }^{40}$ Rolston, “Duties to Ecosystems," p. 258.

${ }^{41}$ Hayek, Law, Legislation and Liberty Vol. II, p. 31.
} 
the causal sense that it the result of millions of different human actions. But if someone were to object on moral grounds to a given distribution, there would be "no individual and no co-operating group of people against which the sufferer would have a just complaint." ${ }^{42}$

Hayek and Rolston thus have diametrically opposed understandings of the relationship between spontaneous order and ethical judgement. For Rolston the diversity and complexity of a spontaneous order contributes to its moral value. For Hayek on the other hand the products of spontaneous order render moral judgements about the orders outcome inoperative. It is a mistake on Hayek's view to say that the complexity of spontaneous orders generates intrinsic value, as the result of the order is better seen as escaping the framework of moral value altogether.

Hayek's analysis here is tied to his rejection of social justice. This aspect of his philosophy is controversial and out of step with how economic distribution is widely viewed in the modern world, namely, as very much a matter of justice. When the notion of spontaneous order is applied to ecosystems, however, the same notion has a more intuitive outcome. There is considerable violence and pain in nature. Predators tear apart prey animals and both predators and prey can be victims of exposure, starvation or fire. We do not normally think we have an obligation to prevent suffering in the wild, even small-scale occurrences we could easily prevent (as by, for example, rescuing small numbers of prey animals from violent deaths and making them our pets, or in some other way looking after them). It is tempting to follow Hayek in saying that such outcomes are beyond morality

\footnotetext{
${ }^{42}$ Hayek, Law, Legislation and Liberty Vol. II, p. 69.
} 
because, as they outcomes of a spontaneous order, no conscious agent or agents brought them about.

As attractive as this response would be, however, I believe it is a mistake. Despite its difference from Rolston Hayek's account of the relationship between spontaneous order and justice suffers from the same problem as Rolston's, in that both theories would seem to ignore the fact-value distinction. It seems no more legitimate to cite facts about the origin of a state of affairs as placing it beyond justice than it does to say they generate intrinsic value. At the least, we are owed more than either Hayek or Rolston offer in regard to why the fact-value distinction does not stymie either analysis.

A second problem emerges when we ask whether we do in fact want to see every product of nature placed beyond justice. To see the issue here, it is helpful to recall the reaction is to predictable natural disasters. If we think of a hurricane, such as the one that struck New Orleans in 2005, it does seem strange to think that the coming of the hurricane was itself an act of injustice. The strangeness is rooted in the reason Hayek offers, namely, that on a modern understanding of the natural world, we do not recognize intentionality in a storm.

Nevertheless, such disasters do give rise to charges of injustice when those in a position to mitigate their destructiveness are perceived not to have done so. Hurricane Katrina, which saw a variety of government agencies accused of serious irresponsibility, is a paradigm example. Such debates are very much carried out in the language of justice, on the grounds that the authorities allowed unnecessary calamities to happen. Hayek seems to allow for such charges of injustice when he refers to injustice that arises as the 
result of someone "allowing it to come about." But if we can be criticized on grounds of justice for not stopping the preventable negative outcomes of spontaneous orders, then the fact that their primary cause was not human does not suffice to place them beyond the reach of justice. We also need to know if there was a human agent who could have stopped their negative outcome but did not.

For the same reason, although we might not feel compelled to stop a wild bear from scooping a salmon into its mouth, were the bear to threaten a human in a manner that we could easily prevent, it does seem wrong of us not to stop it. In both the case of the salmon and the human, the threat is caused by something other than a human agent. This again suggests that the cause by itself is not sufficient grounds to make all judgements of justice concerning spontaneous orders "a category mistake," as Hayek puts it. ${ }^{43}$

In Hayek's work the notion of spontaneous order thus ultimately appears in two separate arguments against central planning. One is based on an epistemological claim about the scope of our ignorance. The other is based on a more purely normative claim about the illusory nature of social justice. The present analysis takes over the first argument but not the second. In this way it affords an additional avenue of escape from Hayek's political conclusions. It also in my view represents a more plausible understanding of the upshot of identifying a complex system, whether ecological or financial, as a spontaneous order. That upshot is one that many environmental ethicists will find amenable, even if it does not entail that plant life has moral standing.

\section{Conclusion}

\footnotetext{
${ }^{43}$ Law, Legislation and Liberty Vol II, p. 32.
} 
The preceding account takes seriously the idea that there is an affinity regarding our ignorance of financial and ecological systems. In both cases there is an element generated from within necessary for the successful function of the entire system, and we do well to let both elements, price and species, find their own level rather than subject either to manipulation. When we do seek to manipulate the natural world, as we inevitably must, we should do so in a manner that seeks as much as possible to preserve the number of species it contains.

Hayek's economic and political philosophy was a product of 1920s Austria and the communist calculation debate that raged in the wake of the Russian Revolution. Lenin and other communists thought that the economy could be subject to central planning, but this turned out not to be the case. Hayek's philosophy rose to prominence in part because it offered an explanation as to why central planning did not work, an explanation many people have found compelling. Today we still struggle to administer economic policies that will advance human welfare-a struggle we should continue, despite Hayek's rejection of social justice. But we are also faced with a new challenge, in the form of the global environmental crisis. It seems reasonable to think that a theory that has borne valuable insights in the economic realm might also yield insights in the ecological one, which is also a realm of great complexity, about which our ignorance is likely to remain permanent and deadly. 